\section{Failing to see dead wood for the trees}

Forests could be emitting more carbon than is believed, because they store large and previously unrecognized quantities of dead wood.

Such wood provides resources for new growth but releases carbon as it decays. Marion Pfeifer at Imperial College London and her team examined the amount of dead wood in 193 plots measuring 25 metres by 25 metres in Sabah, Malaysia. The plots ranged from pristine forest to areas that had been cleared for oil-palm plantations.

The authors estimated that dead wood can hold just 5.4\% of the carbon in some pristine forest, but may contain up to $64 \%$ of the carbon at sites where selected trees had been logged. This value is higher than is often assumed in the literature, they say, suggesting that some estimates of the net amount of carbon trapped by living wood in forests may be too high.

Environ. Res. Lett. 10, 044019 (2015)

\section{Crust crunch leads} to huge quakes

The world's biggest earthquakes can happen in clusters if the geological geometry is right.

Great quakes of

magnitude 8.5 and above occur where one plate of Earth's crust dives beneath another. If the width of plate overlap is particularly wide - more than around 120 kilometres - then even a single huge earthquake cannot relieve all the stress that builds up between the two plates, says a team led by Robert Herrendörfer of ETH Zurich in Switzerland.

The team's modelling suggests that only a series of huge quakes, culminating in a final big one, can overcome the wide plate overlap and relieve seismic stress. This 'supercycle' could explain larger-thanexpected quakes, such as the
2011 Tohoku event in Japan. Supercycles might also occur in regions that have not previously been thought to be at risk, such as Alaska and the Antilles. Nature Geosci. http://dx.doi. org/10.1038/ngeo2427 (2015)

\section{FLUID DYNAMICS}

\section{Instability drives abstract art}

Abstract patterns by Mexican artist David Alfaro Siqueiros are the result of a well-studied problem in fluid dynamics.

Roberto Zenit at the National Autonomous University of Mexico in Mexico City and his team replicated the artist's 'accidental painting' technique, in which layers of paint are poured on a horizontal surface, over time creating whorls, blobs and other shapes. The authors successfully produced patterns similar to those in Siqueiros's work using a dense fluid on top of a light one - an unstable arrangement because the heavier liquid pushes through the light one, forming characteristic shapes.

This 'Rayleigh-Taylor instability' between two fluids has already been widely studied because it is important in many natural and engineering systems. An experimental arrangement similar to that used by Siqueiros could help physicists to advance such studies, the authors say. PLoS ONE http://doi.org/10.1371/ journal.pone.0126135 (2015)

\section{CONSERVATION}

\section{Fossils show extinction risk}

Fossil records can suggest which modern marine species would be at risk of extinction in the absence of human activity.

Seth Finnegan at the University of California, Berkeley, and his team used fossils from the past 23 million years to examine the extinction risk of 2,897 genera from 6 groups - sharks, marine mammals, scleractinia corals, bivalve molluscs, echinoderms such as sea urchins, and snails.

\title{
SOCIAL SELECTION Rommanaridices
}

\section{Sexist review causes Twitter storm}

Scientists on social media have reacted with dismay to a peer reviewer who suggested that a rejected study — which looked at gender differences in postdoctoral job opportunities could be improved by adding a male co-author. Fiona Ingleby, lead author of the still-unpublished study and an evolutionary biologist at the University of Sussex, UK, revealed excerpts of the anonymous review on Twitter on 29 April, setting off a flurry of retweets and responses. "Just in case you thought blatant sexism in academia is gone, look at recent tweets from @FionaIngleby," tweeted Seth Zenz, a particle physicist at

DNATURE.COM

For more on popular papers:

go.nature.com/ekdfay Imperial College London. Caitlin Casey, an astronomer at the University of California, Irvine, tweeted: "And this is one of the reasons we need double-blind refereeing."
They found that small geographic ranges consistently increased extinction risk, and that some broad taxonomic groups had a consistently higher extinction risk than others. Mapping these two features onto modern relatives of these six groups shows the distribution of baseline extinction risk, with hotspots in the Indo-Pacific and Western Atlantic tropics. Overlaps between this baseline and human-derived pressures could point to areas of particular vulnerability.

Science 348, 567-570 (2015)

\section{PHYSICS \\ IceCube gives neutrinos flavour}

High-speed neutrinos detected by the IceCube observatory at the South Pole do come from distant cosmic sources such as galactic nuclei, after all.

Neutrinos are subatomic particles that come in three 'flavours' - electron, muon and tau - which change as they travel over long distances. Previous IceCube data suggested that few muon or tau types had been detected in 2010-12, indicating a possible non-cosmic source or exotic new physics affecting how neutrinos oscillate.

Gary Binder of the
University of California, Berkeley, and his colleagues identified 137 high-energy neutrinos in this date range. They ruled out mainly electron and mainly muon scenarios, concluding that the ratio of flavours is consistent with 1:1:1. This is the expected ratio from neutrinos oscillating over long distances, and further confirms that they originated from distant astrophysical objects.

A separate study by Francesco Vissani at the Gran Sasso Science Institute in L'Aquila, Italy, and his colleagues looked at higherenergy neutrinos detected by IceCube (pictured is one of the sensors in the ice) and also concluded that these are likely to be from cosmic sources. Phys. Rev. Lett. 114, 171102; 171101 (2015)

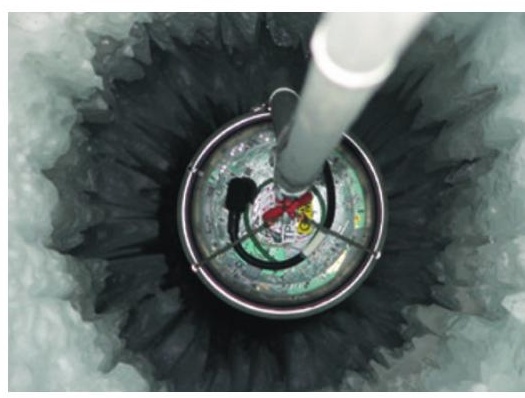

\section{$\rightarrow$ NATURE.COM}

For the latest research published by Naturevisit:

www.nature.com/latestresearch 